\title{
Using PV to help meet Common Property Energy Demand in Residential Apartment Buildings
}

\author{
Mike B Roberts ${ }^{1}$, Gareth Huxham ${ }^{2}$, Anna Bruce ${ }^{1}$ and Iain MacGill ${ }^{3}$ \\ ${ }^{I}$ School of Photovoltaics \& Renewable Energy Engineering, UNSW, Sydney, Australia \\ ${ }^{2}$ EnergySmart Strata, Sydney, Australia \\ ${ }^{3}$ Centre for Energy \& Environmental Markets, School of Electrical Engineering and Telecommunications, \\ UNSW, Sydney, Australia
}

DOI: http://dx.doi.org/10.5130/ssep2016.522

\begin{abstract}
$14 \%$ of Australians live in apartments, predominantly in urban centres, yet few of these have PV systems, despite high levels of PV deployment on separate and semi-detached residential buildings. Increased PV deployment on apartment buildings represents a valuable market opportunity for the PV industry, which would allow apartment dwellers to obtain the financial benefits of using PV to offset electricity bills. PV on apartment buildings could also help relieve network congestion, as it is a good fit with commercial loads commonly found in urban areas, and might therefore benefit network operators as well as households.
\end{abstract}

Some recent high-density residential developments incorporate a PV system for each residential unit, or an embedded network serving all units. However, in existing apartment buildings, as well as physical and other barriers to PV installation[1], legal arrangements can create additional difficulties for individual rooftop PV systems and there may be specific technical and economic barriers to the installation of embedded networks. In these cases, installing PV to supply common property demand (sometimes a high proportion of total building demand) may present a simpler retrofitting opportunity.

Common property load varies significantly between apartment buildings and may include lighting for common areas, and carparks; lifts; water heating and pumping for centralised hot water and pools; air conditioning and ventilation. Its characteristics and diversity are not well understood, with a 2008 DEWHA report identifying the need for further research into communal area energy use in high and medium density housing. Common property energy is typically purchased on behalf of all unit owners by the Owners Corporation, often on commercial tariffs with high ratios of demand to volumetric charges.

We present preliminary findings from a study that utilises the 30-minute common property electricity demand data for 25 apartment buildings in the Sydney metropolitan area. Daily and annual demand profiles are examined and PV systems modelled for each building, sized both for available roofspace and to ensure high levels of onsite consumption. The economic viability of these PV systems is explored using existing retail tariff structures. The findings highlight the potential opportunity for PV to assist in meeting common property load in mediumand hi-rise apartment buildings, and the additional opportunity to supply individual unit loads or sell energy to third parties in medium-rise buildings.

\section{Introduction}

Although Australia has PV penetration reaching $40 \%$ of separate and semi detached residential housing in some Australian cities[2], few of the 1.3 million Australians who live in apartments [3] have access to on-site renewable energy. PV can be deployed on-site to supply individual unit loads, either using independent PV systems for each unit or shared systems distributed through embedded networks or virtual net metering [1]. However, the simplest and most common retrofitted arrangement utilises PV to supply common property (CP) loads only.

There is a limited amount of published data regarding energy loads in Australian apartment buildings. A 2005 report from Energy Australia [4] is often cited in comparisons of energy use as evidence that per-capita energy emissions are highest in high-rise apartment buildings and higher in mid- and low rise apartment buildings than in detached houses, although it is unclear whether these emissions calculations are based solely on total energy use or consider the energy sources utilised. Conversely, a 2010 IPART study [5] suggests that apartments use less energy than detached dwellings, but significantly the comparison does not include common property load in calculations of apartment energy use. 
The Energy Australia report identifies some of its own limitations (disproportionate representation of high rise buildings in its sample despite $72 \%$ of apartments being in buildings of 3 storeys or less [3], reliance on 'walk through' energy audits, etc.), and highlights the difficulty of comparisons across the diverse range of existing multi-occupancy buildings in Australia. In view of this diversity, load data from a significant sample of buildings would be required to statistically capture the variability of load profiles. While it has not been possible to obtain data from large numbers of buildings for this study, using a modest sample of 25 apartment buildings in the Sydney metropolitan region, it has been possible to undertake an initial exploration of the nature and variability of CP loads, and a preliminary analysis of the ability and cost-effectiveness of PV systems to supply common property demand for apartment buildings in the Sydney metropolitan area.

\section{Common Property Loads in Sydney Apartment Buildings}

Existing Australian multi-occupancy housing stock is very diverse in terms of height, construction and facilities. Consequently, common property (CP) loads are highly variable in total energy use and in their daily and monthly profiles. CP demand may include lighting for common areas, stairwells and carparks; lifts; water heating and pumping for centralised hot water and/or for pools; heating, ventilation and air conditioning (HVAC) for common areas and sometimes centralised HVAC for all units. Although CP energy demand can be relatively low in lowrise walk-up apartment buildings, it can account for a large proportion of the total building energy usage in high and medium rise buildings where vertical transportation and communal service area requirements increase markedly.

This study utilises 15- and 30- minute CP load data (initially obtained for the purpose of energy audits) for 25 apartment buildings in the Sydney metropolitan area. Ten of these sites have (ground floor) commercial as well as residential units, but the common property loads do not include any commercial services (with the possible exception of Site 36 where the metering of air-conditioning for the commercial units is unclear). Table 1 shows some characteristics of the sites. (Note that the 25 sites were selected from a larger set on the basis of availability of interval data - hence the non-sequential numbering of the site identifiers.)

Table 1- Summary of Site Characteristics

\begin{tabular}{|c|c|c|c|c|c|c|c|}
\hline $\begin{array}{c}\text { Site } \\
\text { Identifier }\end{array}$ & No. storeys & $\begin{array}{c}\text { Total Units } \\
\text { (Commercial) }\end{array}$ & $\begin{array}{c}\text { Cent ralised } \\
\mathrm{A} / \mathrm{C}\end{array}$ & Pool & $\begin{array}{c}\text { Number of } \\
\text { Lifts }\end{array}$ & $\begin{array}{c}\text { Interval Data } \\
\text { Available (Days) }\end{array}$ & $\begin{array}{c}\text { Building } \\
\text { Footprint }\left(\mathrm{m}^{2}\right)\end{array}$ \\
\hline 1 & 12 & $208(0)$ & No & No & 3 & 485 & 1530 \\
\hline 28 & 4 & $35(6)$ & No & No & 2 & 819 & 1070 \\
\hline 29 & 5 & $35(2)$ & No & No & 2 & 395 & 1220 \\
\hline 30 & 8 & $104(0)$ & No & No & 3 & 394 & 2090 \\
\hline 31 & 4 & $34(0)$ & No & No & 2 & 862 & 1380 \\
\hline 33 & 3 & $43(0)$ & No & No & 4 & 210 & 1490 \\
\hline 34 & 4 & $44(16)$ & No & No & 2 & 181 & 1041 \\
\hline 35 & 5 & $33(6)$ & No & No & 4 & 365 & 1740 \\
\hline 36 & 5 & $116(2)$ & No & No & 2 & 883 & 2510 \\
\hline 37 & 6 & $102(15)$ & No & No & 4 & 365 & 2400 \\
\hline 38 & 9 & $138(0)$ & No & Yes & 4 & 731 & 3660 \\
\hline 40 & 18 & $110(0)$ & Yes & No & 4 & 156 & 1040 \\
\hline 41 & 7 & $161(0)$ & No & Yes & 6 & 365 & 4930 \\
\hline 44 & 5 & $20(0)$ & No & No & 1 & 730 & 1500 \\
\hline 45 & 7 & $121(42)$ & Yes & No & 3 & 268 & 2260 \\
\hline 47 & 5 & $42(1)$ & No & No & 1 & 357 & 1200 \\
\hline 48 & 4 & $44(0)$ & No & No & 0 & 365 & 2250 \\
\hline 50 & 4 & $58(0)$ & No & No & 1 & 170 & 1930 \\
\hline 51 & 3 & $52(0)$ & No & No & 3 & 365 & 3330 \\
\hline 52 & 4 & $48(0)$ & No & No & 0 & 365 & 2620 \\
\hline 53 & 4 & $26(0)$ & No & Yes & 3 & 607 & 1160 \\
\hline 54 & 5 & $20(0)$ & No & No & 2 & 668 & 11290 \\
\hline 55 & 8 & $40(1)$ & Yes & No & 4 & 1156 & 2650 \\
\hline 56 & 20 & $80(0)$ & Yes & Yes & 2 & 548 & 3850 \\
\hline 57 & 20 & $154(4)$ & Yes & Yes & 2 & 365 & 4000 \\
\hline
\end{tabular}


Figure 1 shows the weekday daily common property load profiles averaged over the period of available data for each site, while Figure 2 shows the weekend profiles, which are similar in most cases to the weekday data.

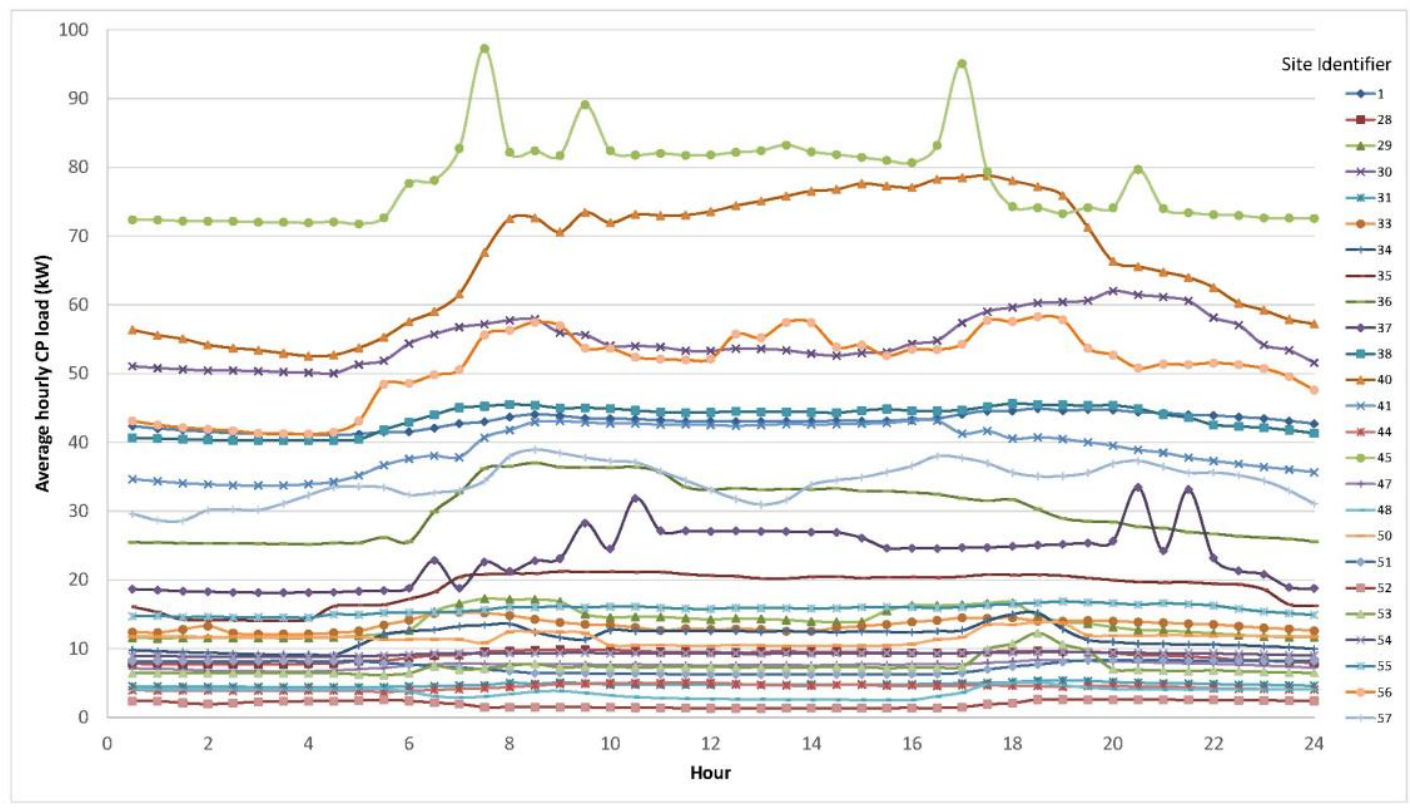

Figure 1-Average weekday CP load profiles

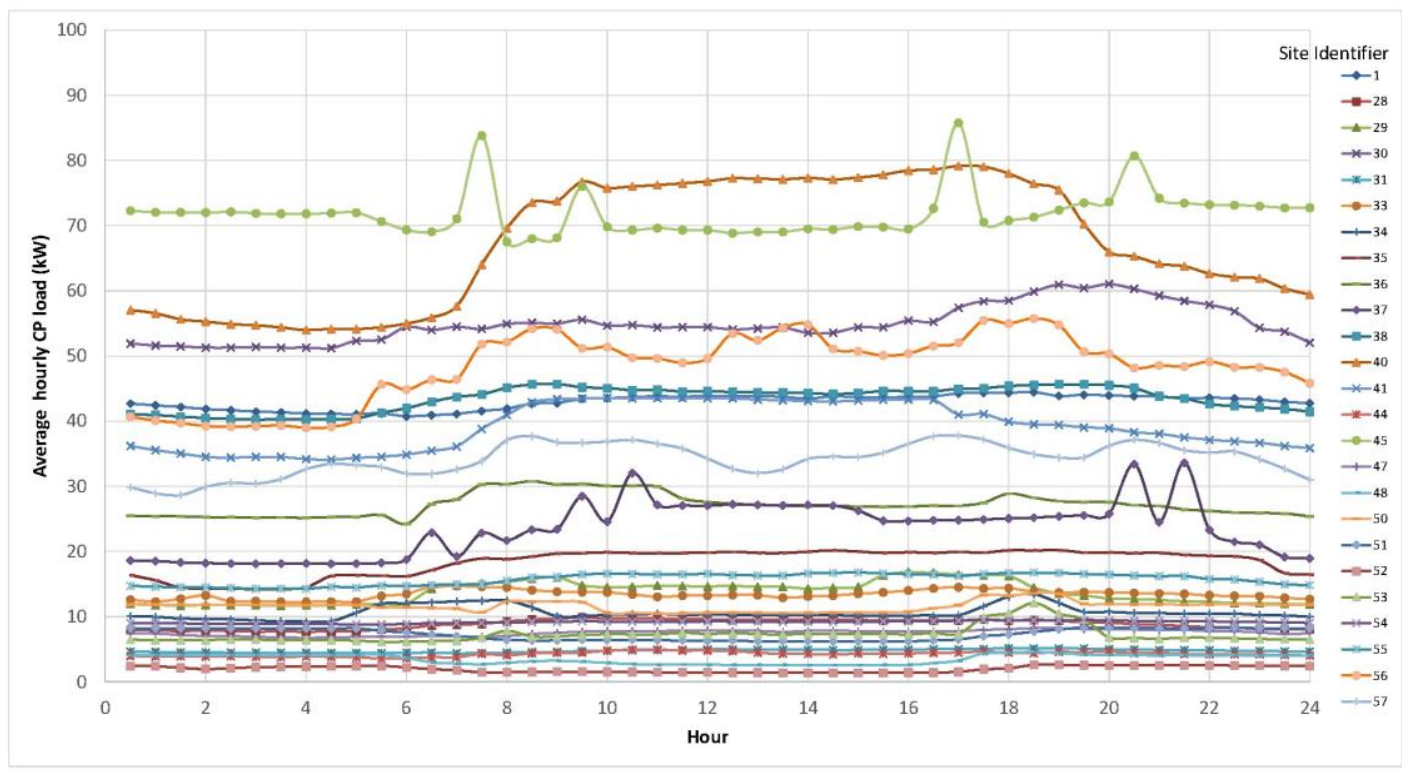

Figure 2-Average weekend load profiles

As is the case for residential building loads in general, daily CP demand is likely to have morning and evening peaks, reflecting increased consumption as residents prepare to leave for, and return from, their daily activities. However, many of the buildings in this study have significant continuous and near constant CP loads that result in relatively flat demand profiles. Figure 3 shows the same profiles for all days normalised for the number of units (residential and commercial) in each building, indicative of the significant variability in common property energy usage beyond that due to the wide range of building sizes. 


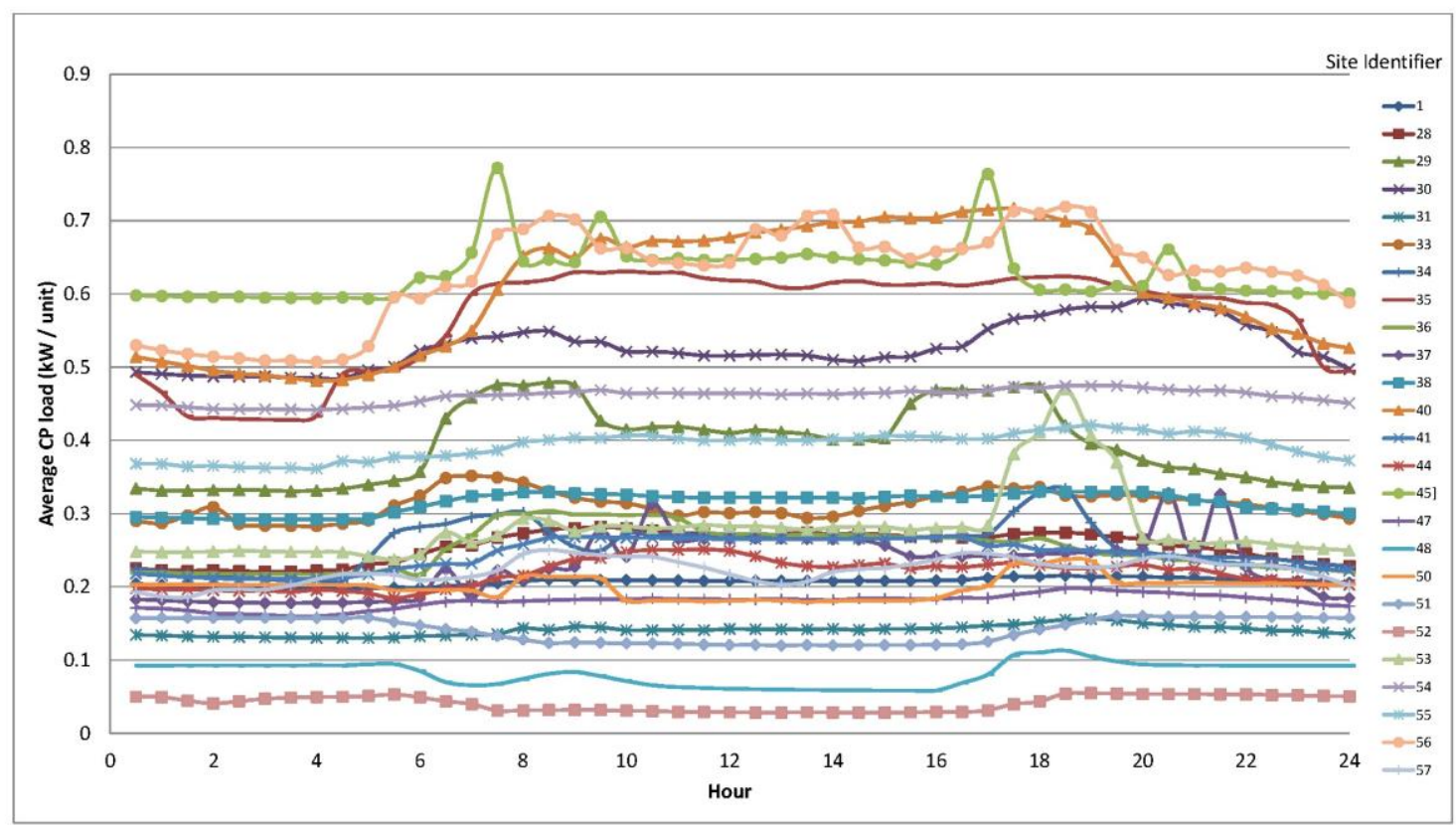

Figure 3 - Average daily load per unit

To provide a basis for the analysis of the suitability of PV systems to meet CP load in Australian apartment buildings, and to add to the thus far limited amount of Australian CP load analysis in the public domain, the remainder of this section explores some of the factors influencing the variability of load profiles in the base dataset. Figures 4 to 10 show the available 30-minute demand data for the common property load at some of the sites. The figures also show the variation in period over which data has been made available for the study.

The seasonal variation shown in Site 56 (Figure 4) is somewhat typical of sites with air-conditioning (A/C) and a pool, while site 45 (Figure 5) shows an increase in demand from February onwards due to ducted heating in the building.

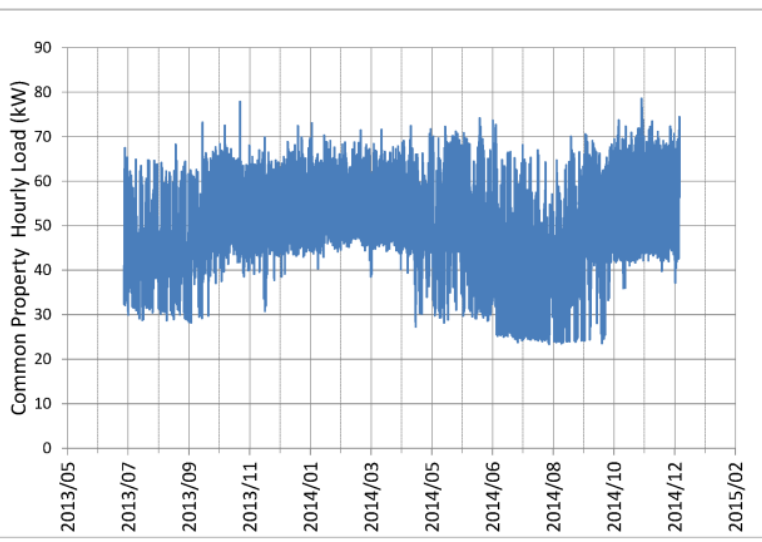

Figure 4 - CP Load for Site 56

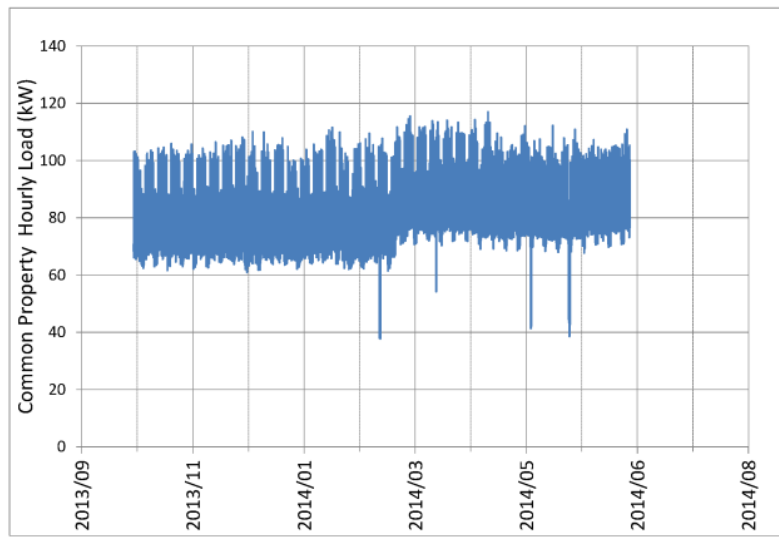

Figure 5 - CP Load for Site 45

The size of the summer spikes for site 35 (Figure 6) is largely due to carpark ventilation fans which are used heavily in summer to vent the heat produced by heat exchangers (located in the underground carpark) for $\mathrm{A} / \mathrm{C}$ in the common lobby areas, while Site 38 (Figure 7) has minimal seasonal variation, but exhibits sporadic spikes all year round as the carpark fans are used for prolonged periods during procedures to unblock sewage pipes. 


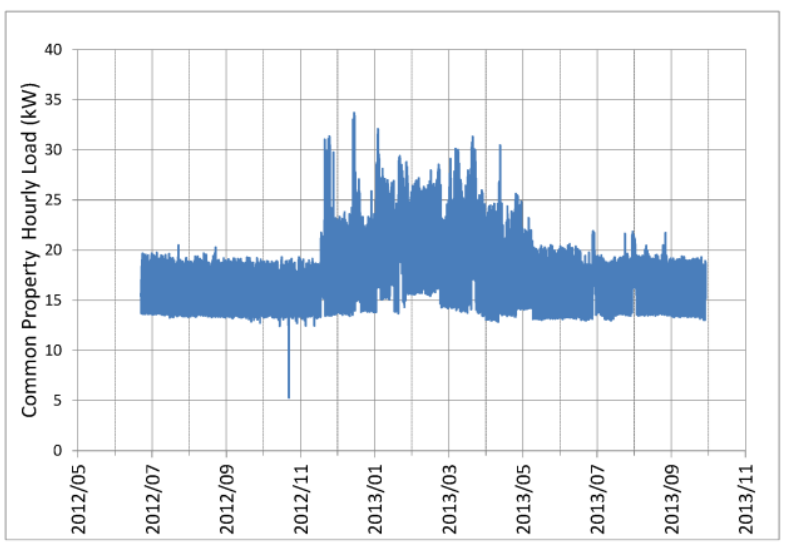

Figure 6-CP Load for Site 35

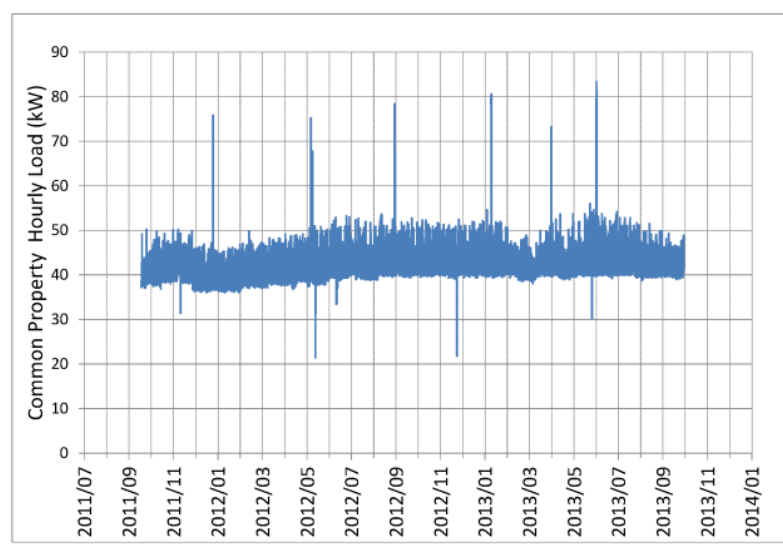

Figure 7 - CP Load for Site 38

Similar control issues with major equipment (often high power ventilation fans and pumps) are evident in many of the sites. For example, sites 1 and 50 (Figure 8 and Figure 9) show increased demand for periods due to faulty timeclocks, also controlling carpark fans. With many sites on tariffs with high demand charges and relatively low supply charges, such control issues can have a major impact on common property energy charges, which are typically passed onto unit owners by the Owners Corporation.

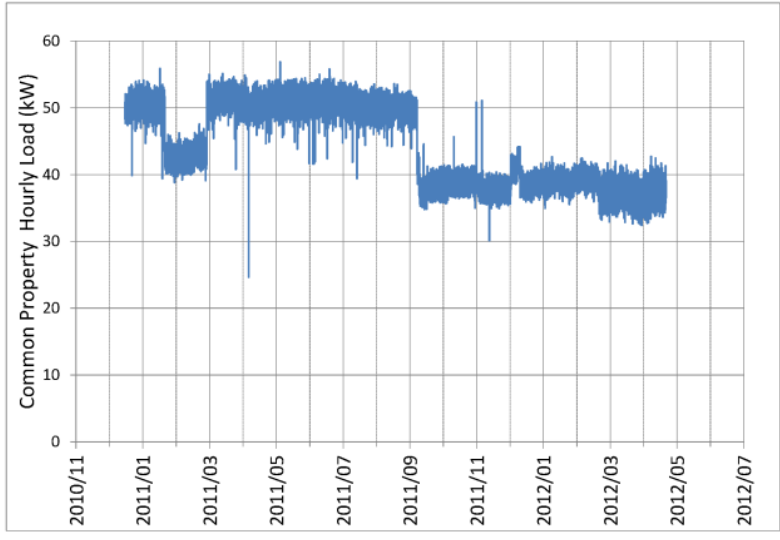

Figure 8 - CP Load for Site 1

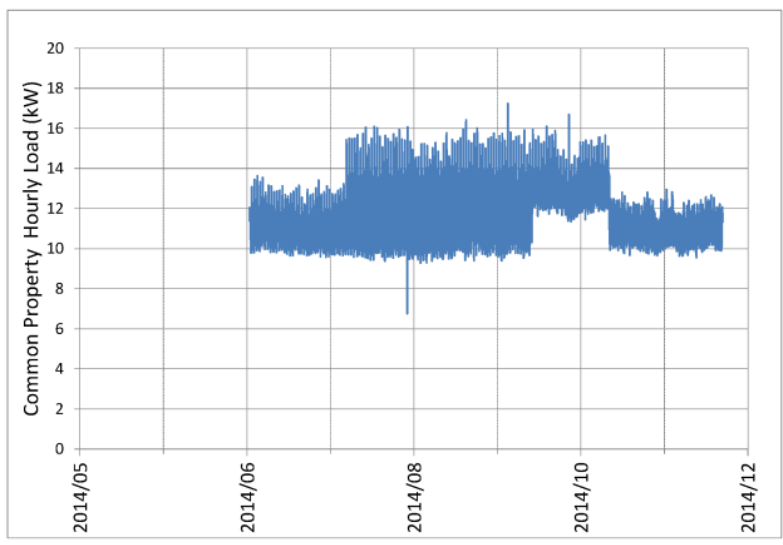

Figure 9-CP Load for Site 50

For those sites with underground carparks, carpark lighting accounted for between $11 \%$ and $51 \%$ of total annual load, with an average of $23 \%$. Figure 10 shows the impact on common property demand of introducing simple energy efficiency measures (LED lighting, motion sensors) at site 31. Total common property load reductions of $40 \%$ or higher through these low cost retrofitted solutions are not uncommon.

This section has explored the variability of CP load profiles in different buildings, depending on the equipment installed and the design and operation of the building. Because of this variability, general conclusions about the use of PV to meet CP loads are hard to reach and further assessment of the opportunities requires specific analysis of generation and load data for case study buildings. The remainder of the paper will present the method and results of a preliminary assessment of the ability of PV to offset CP loads and its cost-effectiveness for this application. 


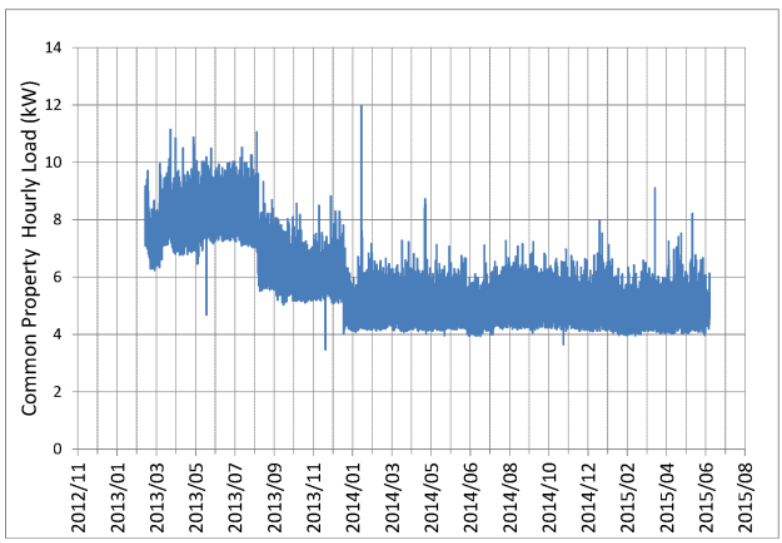

Figure 10 - CP Load for Site 1

\section{Method}

Of the 25 sites in the study, 18 had a full year of load data supplied for a period when hourly weather data was also available. For each of these buildings, two potential PV systems are considered. The first "Full Roof" system approximates to the maximum amount of PV that could be installed on the rooftop of the building. For each building, this system has been designed using Nearmap [6] to fit generic PV modules (250W 1600mm x $1000 \mathrm{~mm}$ ) to the usable roof area. To assess the useable roof area, oblique images of the rooftops were used to estimate the height of projections and a simple geometric model used to calculate shading. In accordance with previous studies [7] and typical calculations used to determine array spacing [8], the arrays have been arranged to avoid shading between $10 \mathrm{am}$ and $2 \mathrm{pm}$ on the winter solstice (the extent of this shading is shown by dark blue lines in Figure 11). Using these criteria, Copper et al [7] calculated that to avoid self-shading, $50 \%-60 \%$ of a horizontal roof surface is usable for mounting latitude-tilted arrays, while arrays flush mounted on a flat roof in Sydney can obtain solar yields of up to $90 \%$ [9]. For this study, therefore, the arrays are mounted flush to the roof surface (or at $2^{\circ}$ to flat roofs) to bypass the need to provide space between modules to avoid self-shading and hence maximise output from the available roof area, although, in the case of large arrays, pathways have been left clear to facilitate access for maintenance. For sloping roofs, sub-systems are arranged with different orientations, flush to each roof surface.

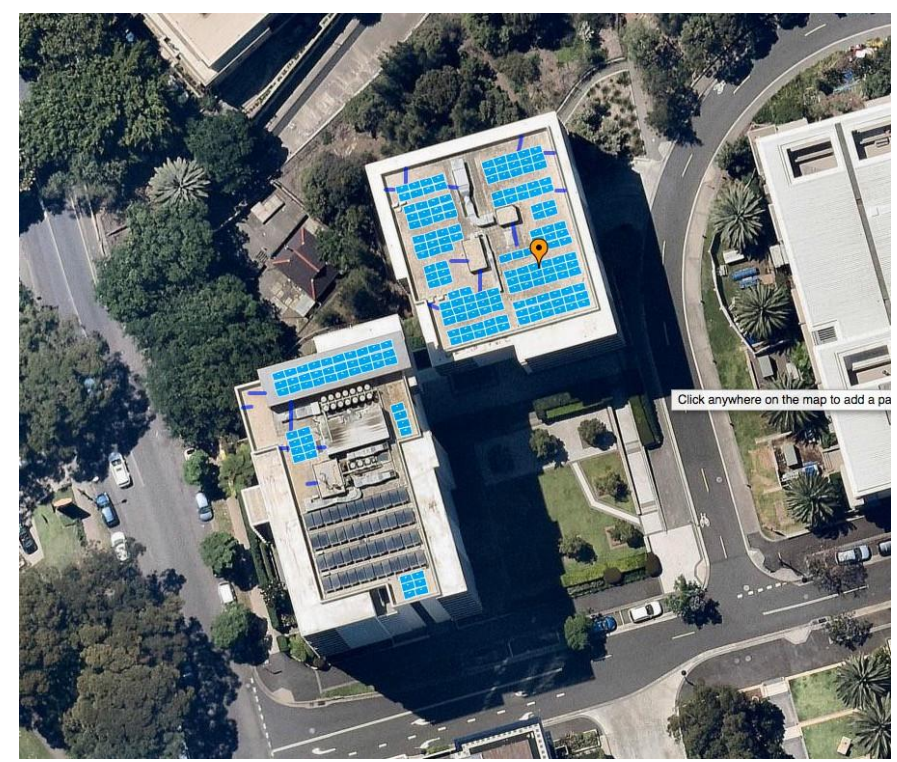

Figure 11 - Example "Full Roof” PV system

The second "Zero Export" system for each building has been sized ignoring building constraints, and matched to the common property load profile to avoid export of more than $0.1 \%$ of PV generated over the year. Although sizing a system for close to $100 \%$ self-consumption may not be financially optimal in many circumstances, this 
arrangement is often used for strata buildings under current regulatory and economic conditions [1] to avoid complexities concerning taxation of export revenue, particularly since export tariffs for PV are typically very low compared to retail tariffs. As an example, the export tariff used for this study is $5.1 \mathrm{c} / \mathrm{kWh}$, compared to peak consumption tariffs that vary between $19.6 \mathrm{c} / \mathrm{kWh}$ and $47.7 \mathrm{c} / \mathrm{kWh}$.

The "Viable" system for each site is the smaller of the two systems modelled. i.e. sized for zero export but constrained by the available unshaded roof area.

The output of each PV system was modelled over a year using the PV Watts model (pvwattsv5[10]) in NREL's System Advisor Model (SAM) [11]. The default values in SAM for system efficiency, degradation, etc. were used. As many of the buildings have some degree of HVAC (whether for common areas or serving units centrally) and / or pools, their common property load can be affected by weather as well as seasonal factors. A real year weather file was created for each site for the same year as the available demand data, utilising Bureau of Meteorology (BOM) gridded satellite-derived irradiance data and weather data from the nearest BOM weather station. Emissions abatement for the largest possible PV ("Full Roof") system at each site was calculated, based on the total annual generation and using an average electricity emissions intensity value of 0.84 tonnes $\mathrm{CO}_{2}$-e /MWh for New South Wales[12]. Only scope 2 emissions are considered (i.e. emissions physically produced by burning of fuels), not scope 3 emissions (those due to the extraction and transportation of the fuel or transmission and distribution of the electricity). Nor has account been made for embodied energy, either of the PV installation or of the power generator and distribution network.

For each site, the 2013 / 2014 published tariff rates (with actual negotiated \% discounts applied as appropriate) were used to calculate financial savings to the Owners Corporation due to reduced energy import and energy export (if any) for the PV systems sized to maximise self-consumption. A simplified analysis of potential demand charge savings was also included although the irregular distribution of large peaks in many of the load profiles makes it difficult to attach any degree of certainty to these estimates. The combined annual savings were used to calculate simple payback periods for the systems, using average \$/W capital costs for NSW [13] (ranging from $\$ 1.24 / \mathrm{W}$ for systems above $50 \mathrm{kWp}$ to $\$ 2.41 / \mathrm{W}$ for the smallest $1.5 \mathrm{~kW}$ system) and the current CP load tariffs for each building, assuming no tariff changes going forward.

\section{Results}

For the 18 sites modelled over a full year, the available roofspace had the capacity to generate an average of $74 \%$ of the common property load, with some of the 3,4 and 5-storey sites having total PV capacity in excess of (and as high as 3 times) annual $\mathrm{CP}$ demand (Figure 12).

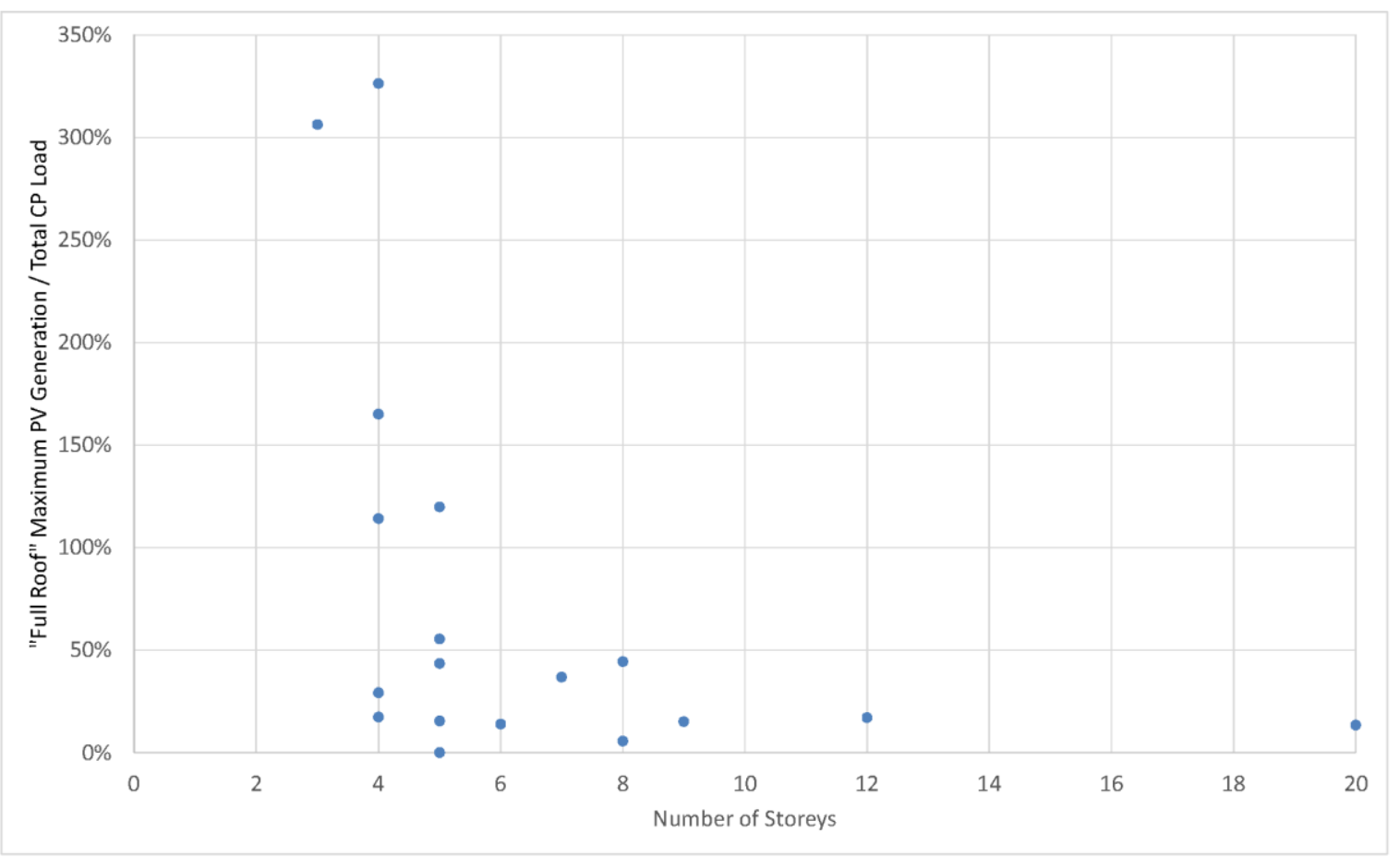

Figure 12 - Maximum potential annual generation as proportion of CP load 
Figure 13 shows the $\mathrm{CO}_{2}$-equivalent GHG emissions that could be avoided each year by installation of the "full roof" PV system for each site (on average $23 \mathrm{~kg} \mathrm{CO}_{2}-\mathrm{e} / \mathrm{m}^{2} /$ year) and demonstrates the variability in the proportion of the building footprint that can be utilised for PV deployment. Figure 14 shows the potential reductions per unit, which have an average value of $1120 \mathrm{~kg} \mathrm{CO}_{2}$-e / unit, with significantly higher reductions possible for some of the medium-rise buildings. This represents $14 \%$ of the ( 8 tonne) average annual household GHG emissions reported in the Energy Australia study. [4]

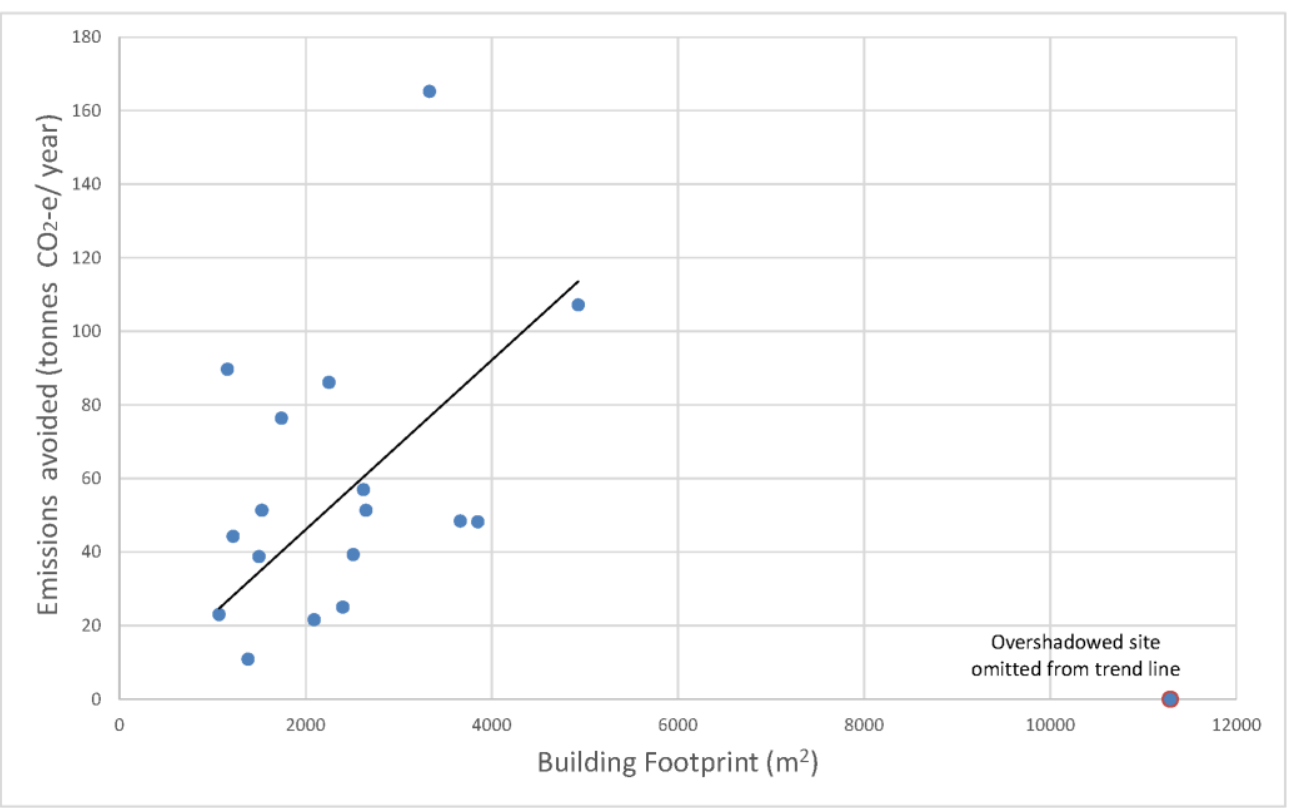

Figure 13 - Potential whole building emissions reductions

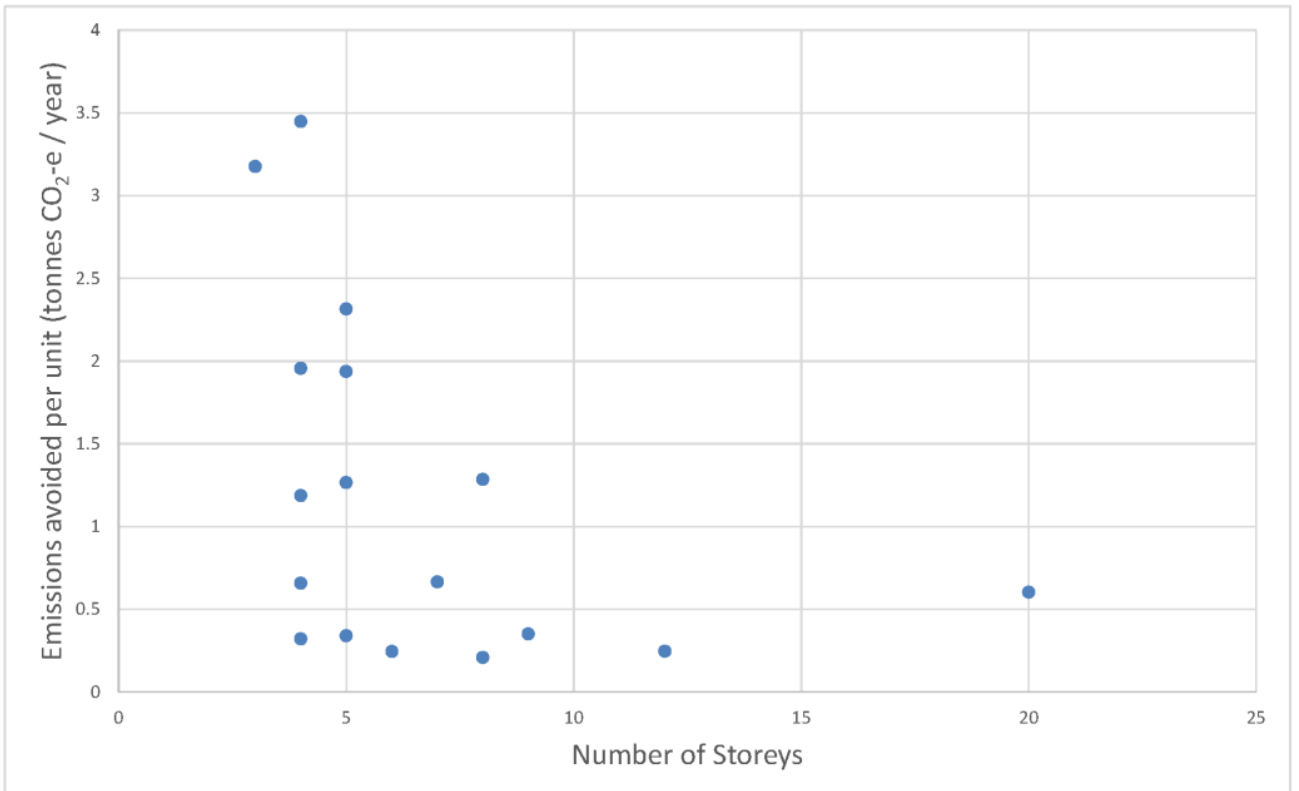

Figure 14 - Potential emissions reductions per unit

In 7 of the 18 sites examined in the study, the "Zero Export" PV system sized to meet CP load without export was larger than the "Full Roof" PV system. However, for the remaining systems, the available roof area was at least sufficient to site a "Zero Export" system, with many medium-rise buildings having a large surplus of potential generation (Figure 15). The latter may be suitable sites for deploying PV to serve loads of individual units in addition to common property, or for deploying storage to offset evening demand. 


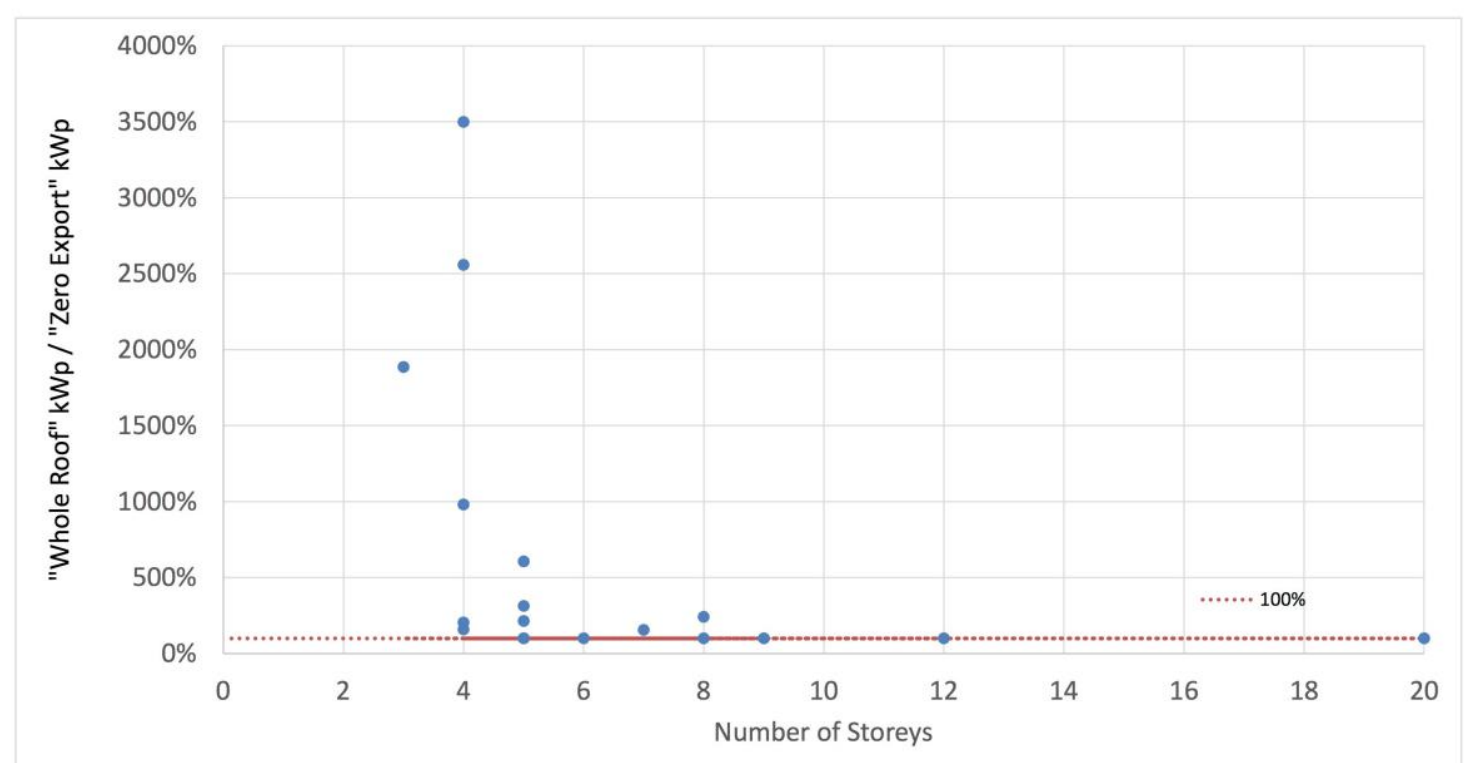

Figure 15 - Ratio of "Full Roof" to "Zero Export” system sizes

The annual electricity bill savings per apartment for installing the "viable" system range from zero (for an overshadowed site) to $\$ 180$ with an average value of $\$ 77$. On average, the non-discounted payback period for the "viable" PV systems would be 5.0 years (but see the discussion below). Although the shortest payback periods were for buildings with 5 storeys or less (Figure 16), no clear relationship was found between payback and building height or building footprint, once again highlighting the diversity of apartment building types and suitability for PV.

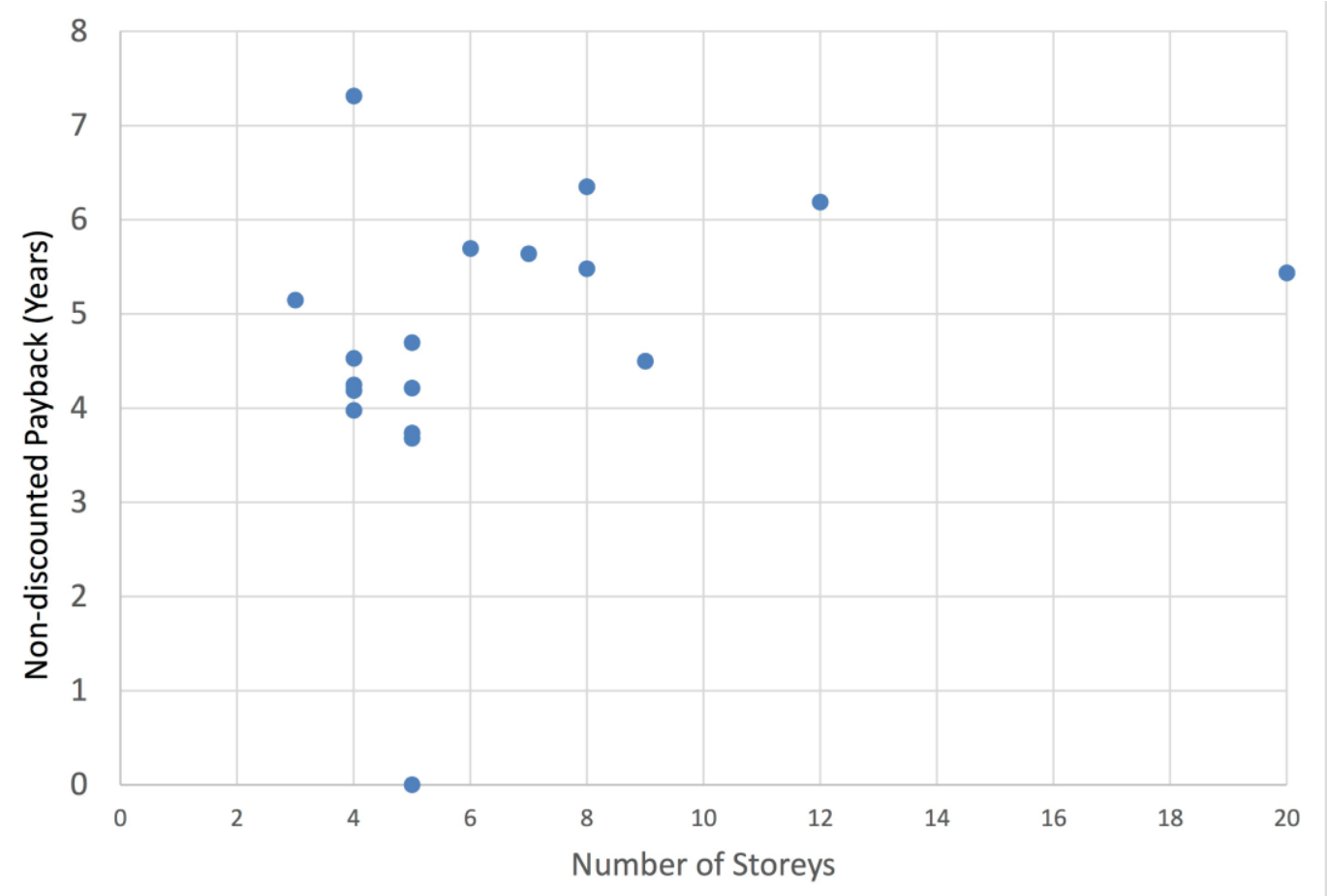

Figure 16 - Simple payback for "Viable” systems

Figure 17 suggests that, as would be expected, non-discounted payback periods are lower for PV systems serving CP loads in buildings with higher average supply tariffs, but a bigger sample would be required to establish any relationship. 


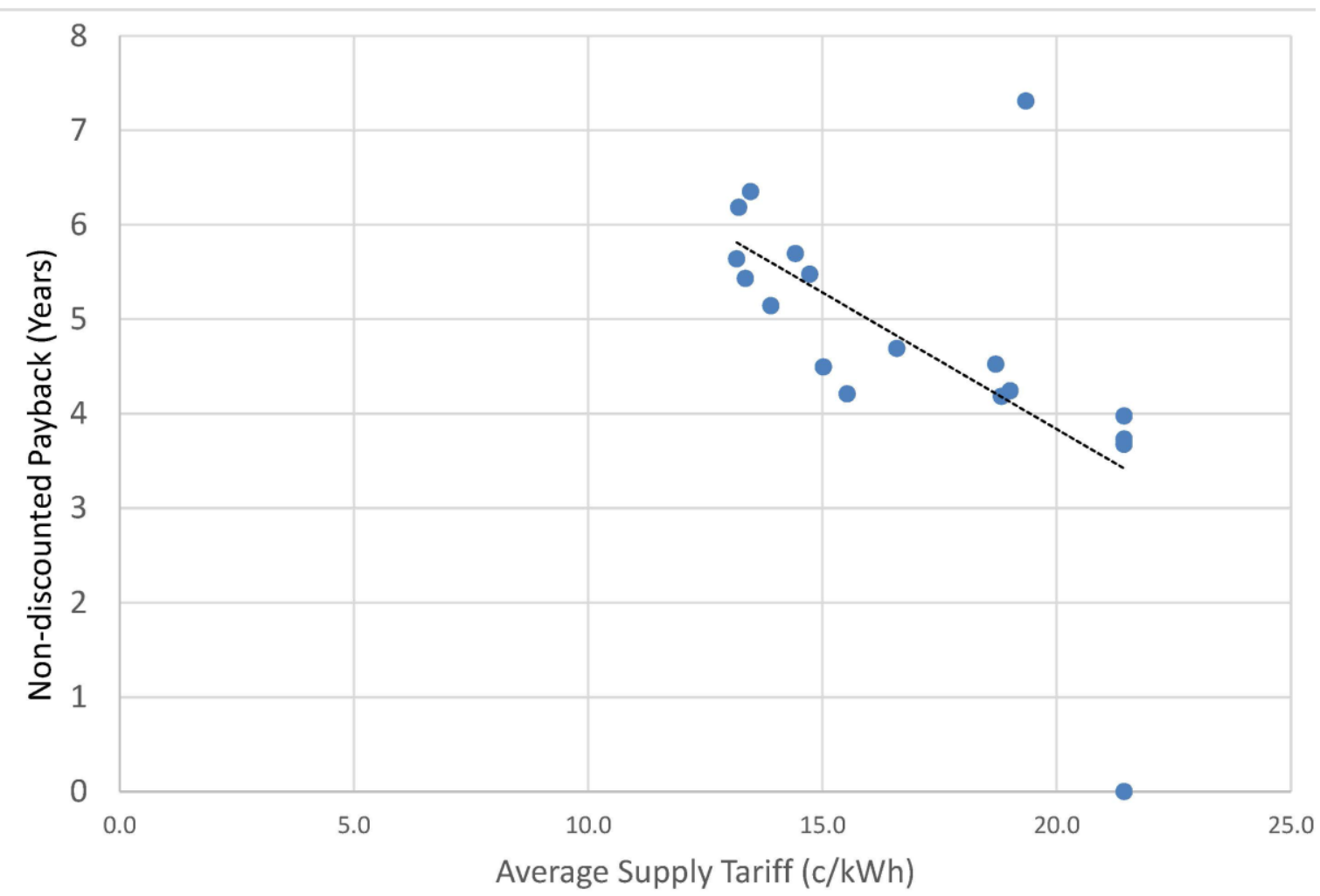

Figure 17- Simple payback for a range of supply tariffs

\section{Discussion \& Further Research}

The results presented here are from a small sample of buildings which is diverse in height, age and type of building stock. A larger sample, with significant numbers in specific subgroups (3 storey walk-ups, medium-rise, high-rise, etc.) is needed for any meaningful statistical analysis. It would also be useful to examine the impact of other building characteristics such as CP floor area and facilities, and to extend the study to include other climatic zones within Australia.

The criteria used for assessing the maximum possible PV system for each site are deliberately intolerant of shading and allow significant roof area for access; as a result they may be overly conservative. As an extreme example, site 33 is completely overshadowed by a neighbouring building at the winter solstice and so has been identified as unsuitable for PV deployment, whilst, in fact, there is a (10kW approx.) PV system installed on this roof (although it is not known whether the neighbouring building existed at the time of the installation). It would be useful to further develop and evaluate the procedure for assessing maximum PV potential, using 3-D building models to calculate shading effects in detail.

On average, the buildings in the study have the potential to generate $74 \%$ of their CP load from that available rooftop area (Table 2). However, the inclusion of a criteria of $99.9 \%$ self-consumption in the definition of a "viable" PV system results in systems that all generate less than $23 \%$ of annual CP load. This highlights the combined impact of low FiTs and tax rulings IT 2505 [14] / TR 2015[15] as barriers to PV deployment [1], which leads to undersizing of PV installations relative to the potential capacity of many sites.

Table 2 - Percentage of CP load met by PV output

\begin{tabular}{|l|l|l|l|}
\hline & Average & Max & Min \\
\hline Maximum "Whole Roof" & $74 \%$ & $326 \%$ & $0 \%$ \\
\hline "Zero Export" & $16 \%$ & $22 \%$ & $3 \%$ \\
\hline "Viable" & $14 \%$ & $22 \%$ & $0 \%$ \\
\hline
\end{tabular}


Although modelling of flush-mounted PV systems is useful for assessing the maximum generation potential for each site, in practice, PV systems are more commonly tilt mounted (particularly on flat roofs) to maximise energy generation per kWp installed. Modelling tilted arrays (with appropriate array spacing to minimise selfshading) may reduce calculated payback periods and this option should be considered when assessing the economic benefits of PV at each site.

On average, $97 \%$ of estimated annual savings from PV systems installed to offset CP electricity bills are due to reductions in supply charges, although for one small site $13 \%$ of the savings are from reduced peak demand. For those sites which show large variability in hourly and daily demand due to high power equipment such as exhaust fans, any reduction in demand charges due to PV is likely to be small in comparison to potential reductions from improved control strategies. Analysis of a significant sample of buildings would be required to appreciate the impact of PV on CP peak loads, particularly given the variability in size and timing of the peak loads.

Although the rudimentary economic analysis (using non-discounted payback) utilised in the study does facilitate a comparison of sites with different characteristics, it has limited use in assessing the real economic benefits of PV deployment. A more sophisticated economic analysis - including a rigorous assessment of the potential impact of PV peak demand charges, a more detailed cost of installation model, and the use of discounted payback or Net Present Value to assess the economic case - would add value to the study.

\section{Conclusion}

The preliminary data from the study suggests that many apartment buildings have the potential for deployment of PV systems that can make a significant contribution to reducing common property energy demand and carbon emissions; and that many of these systems have simple payback periods of 8 years or less. The study also highlights the impact of apartment building energy efficiency and demand management measures on energy costs. However, for some low- and medium- rise buildings, the potential PV generation is larger than can be utilised to meet CP loads economically under existing tariff arrangements. Further study is needed to assess the economic potential of diverting excess generation to storage or to meet unit loads, as well as exploring appropriate deployment models and regulatory arrangements. Estimates of the contribution and value of PV can also be improved in future work by using a larger sample of buildings across a range of Australian climates, more detailed modelling of shading at the site and a more detailed economic analysis.

\section{Acknowledgement}

The authors are grateful to Dr Jessie Copper for assistance in sourcing hourly weather data as well as advice on shading calculations and the use of SAM. 


\section{Glossary}

$\begin{array}{ll}\text { A/C } & \text { Air conditioning } \\ \text { BOM } & \text { Bureau of Meteorology } \\ \text { CP } & \text { Common Property } \\ \text { FiT } & \text { Feed-in Tariff } \\ \text { HVAC } & \text { Heating, Ventilation, Air Conditioning } \\ \text { IPART } & \text { Independent Pricing and Regulatory Tribunal } \\ \text { kWp } & \text { Kilowatt peak } \\ \text { OC } & \text { Owners' Corporation (or Body Corporate) } \\ \text { PV } & \text { Photovoltaic } \\ \text { SAM } & \text { System Advisor Model }\end{array}$

\section{References}

1. Roberts, M.B., A. Bruce, and I. MacGill, PV in Australian Apartment Buildings - Opportunities and Barriers, in Asia Pacific Solar Research Conference. 2015: Brisbane.

2. $\quad$ APVI, Australian PV in Australia Report 2014. 2015, APVI.

3. ABS, Census of Population and Housing. 2011, Australian Bureau of Statistics.

4. Myors, P., R. O'Leary, and R. Helstroom, Multi Unit residential Buildings Energy \& Peak Demand Study. 2005, Energy Australia / NSW Dept of infrastructure, planning \& Natural Resources.

5. IPART, Residential Energy and Water Use in Sydney, the Blue Mountains and Illawarra: Results from the 2010 Household Survey. 2010.

6. Nearmap Ltd. Nearmap. 2015; Available from: http://au.nearmap.com.

7. Copper, J.K., A.B. Sproul, and A.G. Bruce, A method to calculate array spacing and potential system size of photovoltaic arrays in the urban environment using vector analysis. Applied Energy, 2016. 161: p. 11-23.

8. Clean Energy Council, Array Spacing for Pitch Frames. (Clean Energy Council Tech. Info. ), in Copper, J.K., A.B. Sproul, and A.G. Bruce, A method to calculate array spacing and potential system size of photovoltaic arrays in the urban environment using vector analysis. Applied Energy, 2016. 161: p. 11-23. 2010.

9. Prassad, D. and M. Snow, Designing with solar power: A source book for building integrated photovoltaics (BiPV). . 2005: Images Publishing Group.

10. Dobos, A.P., PVWatts Version 5 Manual. 2014.

11. Balir, N.J., P. Gilman, and A. Dobos, Comparison of Photovoltaic Models in the System Advisor Model. 2013, NREL.

12. Commonwealth of Australia (Department of the Environment), National Greenhouse Accounts Factors. 2015.

13. Solar Choice. 2015; Available from: http://www.solarchoice.net.au/blog/news/commercial-solarsystem-prices-november-2015-011215 and http://www.solarchoice.net.au/blog/solar-pv-system-pricesnovember-2015.

14. ATO, Taxation Ruling No. IT 2505. Australian Tax Office.

15. ATO, Draft taxation Ruling TR 2015/D1, ATO, Editor. 2015. 